\title{
Clinical evaluation of stereotactic radiation therapy for recurrent or second primary mediastinal lymph node metastases originating from non-small cell lung cancer
}

\author{
Mao-Bin Meng ${ }^{1, *}$, Huan-Huan Wang ${ }^{1, *}$, Nicholas G. Zaorsky ${ }^{2,}{ }^{,}$, Xian-Zhi Zhao ${ }^{1}$, Zhi- \\ Qiang Wu ${ }^{1}$, Bo Jiang ${ }^{1}$, Yong-Chun Song ${ }^{1}$, Hong-Qing Zhuang ${ }^{1}$, Feng-Tong Li ${ }^{1}$, Lu- \\ Jun Zhao ${ }^{1}$, Chang-Li Wang ${ }^{3}$, Kai Li ${ }^{4}$, Ping Wang ${ }^{1}$ and Zhi-Yong Yuan ${ }^{1}$ \\ ${ }^{1}$ Department of Radiation Oncology, CyberKnife Center, and Key Laboratory of Cancer Prevention and Therapy, Tianjin \\ Medical University Cancer Institute and Hospital, National Clinical Research Center for Cancer, Tianjin, China \\ 2 Department of Radiation Oncology, Fox Chase Cancer Center, Philadelphia, PA, USA \\ 3 Department of Lung Cancer and Key Laboratory of Cancer Prevention and Therapy, Tianjin Medical University Cancer \\ Institute and Hospital, National Clinical Research Center for Cancer, Tianjin, China \\ ${ }^{4}$ Department of Thoracic Oncology and Key Laboratory of Cancer Prevention and Therapy, Tianjin Medical University Cancer \\ Institute and Hospital, National Clinical Research Center for Cancer, Tianjin, China \\ * These authors have contributed equally to this work \\ Correspondence to: Ping Wang, email: doctormm991@hotmail.com
}

Zhi-Yong Yuan, email: zhiyong0524@163.com

Keywords: local control, mediastinum, non-small cell lung cancer, stereotactic body radiation therapy, fractionated stereotactic radiation therapy

Received: December 17, $2014 \quad$ Accepted: March 05, $2015 \quad$ Published: March 30, 2015

This is an open-access article distributed under the terms of the Creative Commons Attribution License, which permits unrestricted use, distribution, and reproduction in any medium, provided the original author and source are credited.

\section{ABSTRACT}

Aims: To evaluate the safety and efficacy of stereotactic radiotherapy (SRT, both stereotactic body RT [SBRT] and fractionated stereotactic RT [FSRT]) in the treatment of patients with recurrent or second primary mediastinal lymph node metastases ( $R$ / SP-MLNMs) originating from non-small cell lung cancer (NSCLC).

Methods: Between 10/2006 and 7/2013, patients with R/SP-MLNMs originating from NSCLC were enrolled and treated with SRT at our hospital; their data was stored in prospectively-collected database. The enrolled patients were divided into Group A (without prior RT) and Group B (with prior RT). The primary end-point was overall survival (OS). The secondary end-points were the MLNM local control (LC), the time to symptom alleviation, and toxicity using the Common Terminology Criteria for Adverse Events (CTCAE v4.0).

Results: Thirty-three patients were treated (16 in Group A with 19 R/SP-MLNMs and 17 in Group B with 17 R/SP-MLNMs). For the entire cohort, the median OS was 25.5 months with a median follow-up of 20.9 months (range, 3.2-82). The 1-year and 3 -year actuarial LC rates were $100 \%$ and $86 \%$, respectively. Symptom alleviation was observed in 52\% of patients, after a median of 6 days (range, 3-18). CTCAE v4.0 $\geq$ Grade 3 toxicities occurred in 5 patients (15\%; all in Group B); among them, Grade 5 in 2 patients.

Conclusions: We recommend exercising extreme caution in using SRT for R/SPMLNMs in patients who received prior RT (particularly to LN station 7). For patients without previous RT, SRT appears to be safe and efficacious treatment modality; prospective studies are warranted. 


\section{INTRODUCTION}

Patients treated with definitive surgical resection for early-stage non-small cell lung cancer (NSCLC) have a $25-35 \%$ rate of nodal metastasis at the time of surgery [1-2]. Similarly, among patients receiving conventionally fractionated external beam radiation therapy (EBRT; with 3D conformal RT [3D-CRT], or intensity modulated RT [IMRT]), the regional nodal failure rate, even when these nodes are not intentional targets, is 5-15\% [3-7]. Recurrent or second primary mediastinal lymph node metastases (R/SP-MLNMs) are challenging for physicians to treat, given their proximity to critical structures (e.g. esophagus, great vessels, and trachea) [8]. Moreover, R/SP-MLNMs (unlike primary parenchymal tumors) are more likely to negatively impact patient quality of life by causing symptoms (e.g. dysphagia, dyspnea, pain) [9].

Currently, there is no standard approach for managing R/SP-MLNMs. Generally, surgical salvage of $\mathrm{R} / \mathrm{SP}-\mathrm{MLNMs}$ is not always feasible because of disease extent or the involvement of critical structures [10]. The National Comprehensive Cancer Network (NCCN) recommends chemo-RT for patients with R/SP-MLNMs if the patients did not receive RT (RT may be delivered as palliative 3D-CRT); and chemo alone if the patients received previous RT. Notably, there is a lack of level I evidence in most situations [11-13]. Palliative EBRT is typically delivered in 2-3 Gy fractions to a total of $30 \mathrm{~Gy}$; unfortunately, the dose is limited because of a relatively high dose of radiation deposited to surrounding structures, causing toxicity.

Stereotactic radiation therapy (SRT) is a type of EBRT that delivers RT accurately and precisely to the tumor, more so than conventionally fractionated IMRT. SRT is divided into stereotactic body RT (SBRT, the delivery of 3.5-15 Gy per fraction, in 5 fractions or less) and fractionated stereotactic RT (FSRT, in more than 5 fractions). The fractionation schemes and treatment machines are juxtaposed in Figure 1. SRT can be delivered either using a traditional linear accelerator or using a robotic arm (i.e. CyberKnife). SRT appears to be an acceptable treatment option for recurrent tumors, and several series report high rates of local control and low incidence of complication in SRT for re-RT of NSCLC [14-18]. We hypothesized that SRT (both FSRT and SBRT) was a safe and efficacious treatment modality for R/SP-MLNMs from NSCLC.

\section{RESULTS}

\section{Patient characteristics}

Clinical information on 1,765 patients treated with SRT between October 12006 and January 132013 at the
CyberKnife Center of Tianjin Medical University Cancer Institute \& Hospital was reviewed. Of these patients, there were 1421 who had NSCLC and were initially evaluated by a multidisciplinary tumor board at our center. There were 33 patients with $36 \mathrm{R} / \mathrm{SP}-\mathrm{MLNMs}$ from NSCLC were subsequently treated with SRT. The patients were divided into Group A (without prior RT; 16 patients with 19 R/SP-MLNMs) and Group B (with prior RT, 17 patients with $17 \mathrm{R} / \mathrm{SP}-\mathrm{MLNMs}$ ). Sixteen patients had 18 R-MLNMs, and 17 patients had 18 SP-MLNMs. For group B, the median interval between initial RT and reRT was 6.7 months (range, 1.1-39.4 months). Table 1 lists patient characteristics. Table 2 lists the MLN station involvement of the patients in this study. Table 3 lists the RT doses, EQD2s, and PTVs of group B.

\section{Treatment characteristics}

The detailed summary of the treatment planning parameters for all patients and each MLNM station are listed in Table 4 and Figure 4. For the whole cohort, the median PTV was $17.89 \mathrm{~mL}$ (range, $4.0-145.0 \mathrm{~mL}$ ). Patients received a median of 5 fractions (range, 3 to 15 fractions) with a median dose of 8 Gy per fraction (range, 3-18 Gy), and a total dose of $45 \mathrm{~Gy}$ (range, 24-60 Gy). The median BED was 83.30 Gy (range, 38-151 Gy). The dose was prescribed to the median $77 \%$ isodose line (range, $70-83 \%$ ), which encompassed $95 \%$ of the PTV.

\section{Overall survival}

For the whole cohort, the median follow-up was 20.9 months (range, 3.2-82). The median OS was 25.5 months; with the 1-year, 3-year, and 5-year OS rates of $72.7 \%, 40.7 \%$, and $20.4 \%$, respectively (Figure 5A). Compared to patients in Group B, patients in Group A had significantly longer median OS (15.3 months vs. 45.0 months, $p=0.01$, Figure 5B). For patients who received SRT $<15.5$ months after their surgery, the median OS was 42.0 months vs. 72.0 months for those treated at a $\geq 15.5$ months interval ( $p=0.03$, Figure 5C). Patients who presented with a R-MLNMs had a median OS of 32.2 months, with 3-year survival rate of $43.8 \%$ vs. 62.2 months and $68.4 \%$ for patients with SP-MLNMs $(p=$ 0.44 , Figure 5D). In addition, the OS showed a slight trend towards superiority of SRT with chemo over SRT without chemo, although these differences were not statistically significant $(p=0.35)$.

\section{R/SP-MLNM response}

Twenty one patients $(21 / 33,64 \%)$ had a CR, 11 patients $(11 / 33,33 \%)$ had a PR, and 1 patient $(1 / 33,3 \%)$ had no response. The 1-year and 3 -year actuarial LC rates 
Table 1: Summary of patient characteristics

\begin{tabular}{|c|c|c|c|}
\hline Parameter & Group A (16 pts) & Group B (17 pts) & All (33 pts) \\
\hline \multicolumn{4}{|l|}{ Age (years) } \\
\hline$<60$ & $7(44 \%)$ & $8(47 \%)$ & $15(45 \%)$ \\
\hline$\geq 60$ & $9(57 \%)$ & $9(53 \%)$ & $18(55 \%)$ \\
\hline \multicolumn{4}{|l|}{ Gender } \\
\hline Male & $11(69 \%)$ & $12(71 \%)$ & $23(70 \%)$ \\
\hline Female & $5(31 \%)$ & $5(29 \%)$ & $10(30 \%)$ \\
\hline \multicolumn{4}{|l|}{ Pathology of primary cancer } \\
\hline Squamous cell carcinoma & $10(63 \%)$ & $7(41 \%)$ & $17(52 \%)$ \\
\hline Adenocarcinoma & $6(37 \%)$ & $4(24 \%)$ & $10(30 \%)$ \\
\hline Large cell carcinoma & 0 & $2(12 \%)$ & $2(6 \%)$ \\
\hline Other $^{\dagger}$ & 0 & $4(23 \%)$ & $4(12 \%)$ \\
\hline \multicolumn{4}{|l|}{ Location of primary cancer } \\
\hline Right upper lobe & $6(38 \%)$ & $2(12 \%)$ & $8(24 \%)$ \\
\hline Right middle lobe & $1(6 \%)$ & $1(6 \%)$ & $2(6 \%)$ \\
\hline Right lower lobe & $2(13 \%)$ & $3(18 \%)$ & $5(15 \%)$ \\
\hline Left upper lobe & $5(31 \%)$ & $7(41 \%)$ & $12(36 \%)$ \\
\hline Left lower lobe & $2(12 \%)$ & $4(23 \%)$ & $6(19 \%)$ \\
\hline \multicolumn{4}{|c|}{ Radiographic appearance of primary cancer } \\
\hline Nodular & $13(81 \%)$ & $16(94 \%)$ & $29(85 \%)$ \\
\hline Infiltrative & $3(19 \%)$ & $1(6 \%)$ & $4(15 \%)$ \\
\hline \multicolumn{4}{|l|}{ Initial stage* } \\
\hline $\mathrm{I} / \mathrm{II}$ & $10(63 \%)$ & $1(6 \%)$ & $11(33 \%)$ \\
\hline IIIA & $6(37 \%)$ & $5(29 \%)$ & $11(33 \%)$ \\
\hline IIIB & 0 & $11(65 \%)$ & $11(34 \%)$ \\
\hline \multicolumn{4}{|l|}{ No. of R/SP-MLNMs } \\
\hline 1 & $14(88 \%)$ & $16(94 \%)$ & $30(91 \%)$ \\
\hline$>1$ & $2(12 \%)$ & $1(6 \%)$ & $3(9 \%)$ \\
\hline \multicolumn{4}{|l|}{ MLNM type } \\
\hline Recurrence & $5(31 \%)$ & $12(71 \%)$ & $17(52 \%)$ \\
\hline Second primary & $11(69 \%)$ & $5(29 \%)$ & $16(48 \%)$ \\
\hline \multicolumn{4}{|l|}{ Clinical symptoms of R/SP-MLNMs } \\
\hline Yes & $5(31 \%)$ & $12(71 \%)$ & $17(52 \%)$ \\
\hline No & $11(69 \%)$ & $5(29 \%)$ & $16(48 \%)$ \\
\hline \multicolumn{4}{|l|}{ Synchronous metastases } \\
\hline Yes & $5(31 \%)$ & $3(18 \%)$ & $8(24 \%)$ \\
\hline No & $11(69 \%)$ & $14(82 \%)$ & $25(76 \%)$ \\
\hline \multicolumn{4}{|l|}{ Radiographic diagnosis R/SP-MLNMs } \\
\hline PET-CT & $9(56 \%)$ & $10(59 \%)$ & $19(58 \%)$ \\
\hline $\mathrm{CT}$ & $7(44 \%)$ & $7(41 \%)$ & $14(42 \%)$ \\
\hline \multicolumn{4}{|l|}{ Recurrent staging* } \\
\hline II & $1(6 \%)$ & 0 & $1(3 \%)$ \\
\hline III & $10(63 \%)$ & $14(82 \%)$ & $24(73 \%)$ \\
\hline IV & $5(31 \%)$ & $3(18 \%)$ & $8(24 \%)$ \\
\hline \multicolumn{4}{|l|}{ Time to recurrence (months) } \\
\hline$<15.5$ & $7(44 \%)$ & $4(24 \%)$ & $11(33 \%)$ \\
\hline$\geq 15.5$ & $9(56 \%)$ & $13(76 \%)$ & $22(67 \%)$ \\
\hline \multicolumn{4}{|l|}{ Therapy prior to $\mathrm{SRT}^{\S}$} \\
\hline $\mathrm{S}$ & $16(100 \%)$ & $11(65 \%)$ & $27(82 \%)$ \\
\hline $\mathrm{CT}$ & $10(63 \%)$ & $14(82 \%)$ & $24(73 \%)$ \\
\hline RT & 0 & $17(100 \%)$ & $17(52 \%)$ \\
\hline
\end{tabular}




\begin{tabular}{|c|c|c|c|}
\hline MTT & $1(6 \%)$ & 0 & $1(3 \%)$ \\
\hline Therapy after SRT§ & & & \\
\hline CT & $6(38 \%)$ & $8(47 \%)$ & $14(42 \%)$ \\
\hline MTT & $1(6 \%)$ & $2(12 \%)$ & $3(9 \%)$ \\
\hline None & $10(63 \%)$ & $7(41 \%)$ & $17(52 \%)$ \\
\hline
\end{tabular}

Note: Group A: Patients with R/SP-MLNMs who received treatment including surgery and/or chemotherapy, but not radiation therapy; Group B: Patients with R/SP-MLNMs who received treatment including surgery and/ or chemotherapy, and radiation therapy

${ }^{\dagger}$ Other is defined as the various combinations of squamous cell carcinoma, adenocarcinoma, and large cell carcinoma.

$¥$ The AJCC (6th edition) was used for staging.

$\S$ Some patients had more than one therapy.

Abbreviations: Pts: patients; R/SP-MLNMs: recurrent or second primary mediastinal lymph node metastases; PET-CT: positron emission tomography/computed tomography; CT: computed tomography; SRT: stereotactic radiation therapy; S: surgery; CT: chemotherapy; RT: radiotherapy; MTT: molecular targeted therapy.

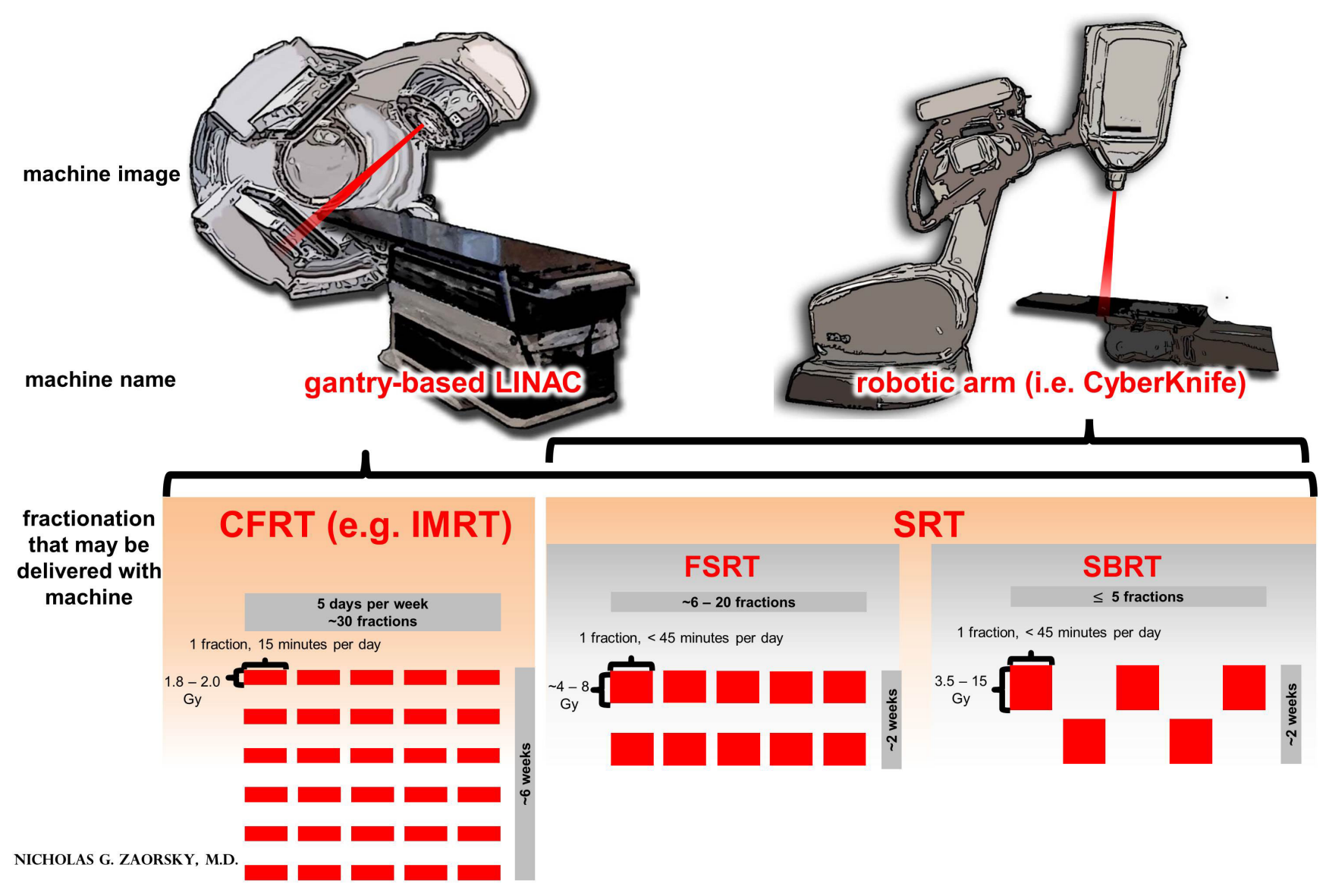

Figure 1: A comparison of treatment machines and fractionation options in external beam radiation therapy (EBRT) for non-small cell lung cancer (NSCLC). Legend: typically, in the primary treatment of NSCLC, EBRT is delivered as conventionally fractionated RT (CFRT), which is $1.8-2.0$ Gy per day, one fraction per day, for a total of $\sim 30$ fractions, to a total dose of $\sim 60$ Gy; CFRT is delivered with intensity modulated RT (IMRT). Stereotactic radiation therapy (SRT) is a type of EBRT that delivers RT accurately and precisely to the tumor, more so than CFRT with IMRT. SRT may be used for small (i.e. T1-2) or recurrent / second primary mediastinal lymph node metastases (R/SP-MLNMs, as in the current work). SRT is divided into stereotactic body RT (SBRT, the delivery of 3.5-15 Gy per fraction, in 5 fractions or less) and fractionated stereotactic RT (FSRT, in more than 5 fractions). SRT may be delivered with a gantrybased LINAC or with a robotic arm LINAC (i.e. a CyberKnife). 
Table 2: LN stations of R/SP-MLNMs

\begin{tabular}{|c|c|c|c|}
\hline Nodal zone & Group A (16 pts) ${ }^{\dagger}$ & Group B (17 pts) & All (33 pts) \\
\hline Upper & $9(47 \%)$ & $7(41 \%)$ & $16(44 \%)$ \\
\hline $1 \mathrm{R}$ & 1 & 0 & 1 \\
\hline $1 \mathrm{~L}$ & 0 & 1 & 1 \\
\hline $2 \mathrm{R}$ & 1 & 0 & 1 \\
\hline $2 \mathrm{~L}$ & 0 & 1 & 1 \\
\hline $3 \mathrm{~A}$ & 1 & 0 & 1 \\
\hline $3 \mathrm{P}$ & 1 & 0 & 1 \\
\hline $4 \mathrm{R}$ & 4 & 2 & 6 \\
\hline $4 \mathrm{~L}$ & 1 & 3 & 4 \\
\hline Aorticopulmonary & $3(16 \%)$ & $4(24 \%)$ & $7(19 \%)$ \\
\hline 5 & 1 & 2 & 3 \\
\hline 6 & 2 & 2 & 4 \\
\hline Subcarinal & $2(11 \%)$ & $4(24 \%)$ & $6(17 \%)$ \\
\hline 7 & 2 & 4 & 6 \\
\hline Lower & $1(5 \%)$ & $1(6 \%)$ & $2(6 \%)$ \\
\hline 9R & 1 & 1 & 2 \\
\hline $9 \mathrm{~L}$ & 0 & 0 & 0 \\
\hline Hilar-interlobar & $4(21 \%)$ & $1(5 \%)$ & $5(14 \%)$ \\
\hline $10 \mathrm{R}$ & 2 & 0 & 2 \\
\hline $10 \mathrm{~L}$ & 2 & 1 & 3 \\
\hline All & $19(100 \%)$ & $17(100 \%)$ & $36(100 \%)$ \\
\hline
\end{tabular}

Note: Group A: Patients with R/SP-MLNMs who received treatment including surgery and/or chemotherapy, but not radiation therapy; Group B: Patients with R/SP-MLNMs who received treatment including surgery and/or chemotherapy, and radiation therapy

There were three patients with more than one R/SP-MLNM. Among these patients, one patient with R/ SP-MLNMs had involvement of the 4R and 9 stations, one patient with R/SP-MLNMs had involvement of the $3 \mathrm{~A}$ and 6 stations, and one patient with R/SP-MLNMs had involvement of the 1R, 2R, 3P, and 7 stations, respectively.

\$There was one patient with R/SP-MLNMs with involvement of the stations 5 and 7.

Abbreviations: R/SP-MLNMs: recurrent/second primary mediastinal lymph node metastases; Pts: patients; R: right; L: left.

for all eligible patients were $100 \%$ and $86 \%$, respectively. The rates of $\mathrm{CR}$ and locoregional control were better in patients with SP-MLNMs vs. those with R-MLNMs ( $p=$ $0.02)$.

\section{The time to symptom alleviation}

The most common symptoms were cough, shortness of breath, hoarseness, and difficulty swallowing. An improvement in symptoms was observed after a median follow-up of 6 days (range, 3-18) in 52\% of patients. Symptom alleviation remained throughout the follow-up period.

\section{Patterns of failure}

No patient failed within the R/SP-MLNM PTV. Five patients $(5 / 33,15 \%)$ had no progression after SRT (all in Group A); there were 17 patients $(17 / 33,52 \%$; 5 in Group A and 12 in Group B) who had progression, with a median of 16.9 months after SRT (range, 2.7-75.5 months). Among the patients with progression, one patient (with station 7 R-MLNM in Group B) had diffuse progression including regional failure. The remaining patients had distant metastases to liver, lung, bone, brain, and nonregional lymph nodes.

\section{Toxicities}

Toxicity of all patients is summarized in Table 5. Six patients (18\%) experienced CTCAE v4.0 Grade 1 to 2 acute toxicities including pneumonitis, esophagitis, tracheitis, chest pain, agranulocytosis, and thrombocytopenia. Three patients (9\%) experienced Grade 3 acute toxicities including esophagitis and tracheitis. Almost all of these acute toxicities occurred in Group B, and they were generally transient and resolved with conservative management. Late radiation toxicities were observed in 4 patients (12\%), all in Group B; 2 patients $(6 \%)$ died from Grade 5 late toxicities. Both patients were treated to LN station 7. One patient died of 
Table 3: An overview of the treatment schedules for NSCLC patients with R/SP-MLNMs receiving SRT (Group B)

\begin{tabular}{|c|c|c|c|c|c|c|c|c|c|c|c|c|c|}
\hline \multirow[b]{2}{*}{$\begin{array}{l}\text { Patient } \\
\text { initials }\end{array}$} & \multicolumn{5}{|c|}{ Re-irradiation } & \multirow{2}{*}{$\begin{array}{l}\text { Interval } \\
\text { months }\end{array}$} & \multicolumn{5}{|c|}{ First radiation } & \multicolumn{2}{|c|}{\begin{tabular}{|l|l|} 
Total dose \\
(sum of previous \\
doses)
\end{tabular}} \\
\hline & $\begin{array}{l}\text { Total } \\
\text { dose } \\
\text { (Gy) }\end{array}$ & $\begin{array}{l}\text { No. of } \\
\text { fractions }\end{array}$ & $\begin{array}{l}\text { EQD2 } \\
\alpha / \beta=10\end{array}$ & $\begin{array}{l}\text { EQD2 } \\
\alpha / \beta=3\end{array}$ & $\begin{array}{l}\text { PTV } \\
\text { (mL) }\end{array}$ & & \begin{tabular}{|l|} 
Total \\
dose \\
(Gy)
\end{tabular} & $\begin{array}{l}\text { No. of } \\
\text { fractions }\end{array}$ & $\begin{array}{l}\text { EQD2 } \\
\alpha / \boldsymbol{\beta}=10\end{array}$ & $\begin{array}{l}\text { EQD2 } \\
\boldsymbol{\alpha} / \boldsymbol{\beta}=\mathbf{3}\end{array}$ & $\begin{array}{l}\text { PTV } \\
(\mathrm{mL})\end{array}$ & $\begin{array}{l}\text { EQD2 } \\
\alpha / \beta=10\end{array}$ & $\begin{array}{l}\text { EQD2 } \\
\alpha / \boldsymbol{\beta}=3\end{array}$ \\
\hline WYC & 30 & 6 & 45 & 80 & 26.19 & 4.1 & 42 & 21 & 50.4 & 70 & - & 95.4 & 150 \\
\hline WJF & 60 & 30 & 72 & 100 & - & 3.1 & 50 & 10 & 75 & 133 & 28.30 & 147 & 233 \\
\hline TBW & 60 & 5 & 132 & 300 & 17.89 & 6.3 & 60 & 30 & 72 & 100 & - & 204 & 400 \\
\hline LSS & 1.8 & 1 & 2.12 & 2.88 & - & 9.0 & 45 & 10 & 65.25 & 112.5 & 15.89 & 67.37 & 115.35 \\
\hline TYJ & 60 & 15 & 84 & 140 & 7.95 & 9.1 & 50 & 20 & 62.5 & 91.67 & - & 146.5 & 231.67 \\
\hline ZXM & 24 & 4 & 38.4 & 72 & 15.85 & 5.5 & 60 & 30 & 72 & 100 & - & 110.4 & 172 \\
\hline ZXL & 36 & 4 & 68.4 & 144 & 50.63 & 1.1 & 29.2 & 7 & 41.38 & 69.79 & - & 109.78 & 213.79 \\
\hline ZXZ & 40 & 7 & 62.86 & 116.19 & 144.93 & 5.9 & 63 & 30 & 76.23 & 107.1 & - & 139.09 & 223.29 \\
\hline LJX & 30 & 10 & 39 & 60 & 71.84 & 6.5 & 45 & 18 & 56.25 & 82.5 & - & 95.25 & 142.5 \\
\hline LYS & 42 & 6 & 71.4 & 140 & 12.90 & 7.3 & 50 & 25 & 60 & 83.33 & - & 131.4 & 223.33 \\
\hline DXR & 61.6 & 28 & 75.15 & 106.77 & - & 19.1 & 48 & 8 & 76.8 & 144 & 32.52 & 151.95 & 250.77 \\
\hline DJG & 67.5 & 27 & 84.38 & 123.75 & - & 39.4 & 45 & 5 & 85.5 & 180 & 50.22 & 169.88 & 303.75 \\
\hline WFL & 60 & 30 & 72 & 100 & - & 6.7 & 40 & 5 & 72 & 146.67 & 3.70 & 144 & 246.67 \\
\hline \begin{tabular}{|l|} 
WSM \\
\end{tabular} & 45 & 6 & 78.75 & 157.5 & 20.02 & 8.1 & 60 & 30 & 72 & 100 & - & 150.75 & 257.5 \\
\hline CGL & 45 & 5 & 85.5 & 180 & 15.72 & 7.8 & 64 & 32 & 76.8 & 106.67 & - & 162.3 & 286.67 \\
\hline ZGL & 54 & 3 & 151.2 & 378 & 11.90 & 6.3 & 60 & 30 & 72 & 100 & - & 223.2 & 478 \\
\hline LEP & 36 & 3 & 79.2 & 180 & 30.27 & 17.8 & 66 & 33 & 79.2 & 110 & - & 158.4 & 290 \\
\hline
\end{tabular}

Abbreviations: EQD2: Equivalent dose in 2 Gray per fraction, based on the formuland $((\mathrm{d}+\alpha / \beta) /(2+\alpha / \beta))$, where $\mathrm{n}$ is number of fractions, and d is dose/fraction (Gy); GTV: Gross tumor volume; PTV: Planning target volume.

Table 4: Summary of SRT treatment parameters.

\begin{tabular}{|c|c|c|c|}
\hline & Group A (16 pts) & Group B (17 pts) & All (33 pts) \\
\hline Parameter (unit) & median (range) & median (range) & median (range) \\
\hline PTV (mL) & $11.81(7-86)$ & $23.11(4-145)$ & $17.89(4-145)$ \\
\hline Prescription dose (Gy) & $48(35-56)$ & $41(24-60)$ & $45(24-60)$ \\
\hline Number of fractions & $5(3-8)$ & $6(3-15)$ & $5(3-15)$ \\
\hline Dose per fraction (Gy) & $9(6-15)$ & $6(3-18)$ & $8(3-18)$ \\
\hline BED $($ Gy) & $85.50(60-112)$ & $71.70(38-151)$ & $83.30(38-151)$ \\
\hline Prescription isodose line, $\%$ & $77(70-83)$ & $76(72-81)$ & $77(70-83)$ \\
\hline
\end{tabular}

Note: Group A: Patients with R/SP-MLNMs who received treatment including surgery and/or chemotherapy, but not radiation therapy; Group B: Patients with R/SP-MLNMs who received treatment including surgery and/or chemotherapy, and radiation therapy

Abbreviations: SRT: stereotactic radiation therapy; Pts: patients; PTV: planning target volume; Gy: Gray; $\mathrm{BED}_{10}$ : biologically effective dose at $\alpha / \beta$ value of 10 .

tracheoesophageal fistula five weeks after completion of re-RT, and the second patient died of tracheoesophageal fistula six weeks after completion of re-RT.

\section{DISCUSSION}

Locoregional recurrence of NSCLC after surgery occurs in approximately $20 \%$ of patients with stage I disease [29-30] and in up to $50 \%$ of patients with stage III disease [31-32]; the majority of failures are confined to the thorax. Currently, the NCCN guidelines recommended that patients with R/SP-MLNMs without prior RT receive chemo-RT because the same treatment approach would be used for inoperable MLNM patients.
For patients who have already received RT, chemotherapy alone is recommended [11]. In the 1990s and 2000s, reports suggested that patients in patients who had disease involving the MLNs, the levels of disease are independent predictors of patient outcome; subsequently, clinicians have argued to treat these recurrences aggressively, though treatment approaches have been heterogenous [33-35]. This is the first study to evaluate the safety and efficacy of SRT (both SBRT and FSRT) for patients with R/SPMLNMs from NSCLC.

In the present study, the median OS for patients with R/SP-MLNMs treated with SRT was 25.5 months (Figure $5 \mathrm{~A})$; this is superior to the OS 11-19 months in patients with R/SP-MLNM using conventional radiotherapy 
Table 5: Toxicities of patients with R/SP-MLNMs treated with SRT.

\begin{tabular}{|l|l|l|l|l|l|l|l|l|l|l|l|l|l|}
\hline & \multicolumn{4}{l}{ Group A, $\mathbf{n}(\%)$} & \multicolumn{3}{l|}{ Group B, $\mathbf{( \% )}$} & \multicolumn{3}{l|}{ Total, n (\%) } \\
\hline Acute toxicities & $\begin{array}{l}\text { Any } \\
\text { Grade }\end{array}$ & $\begin{array}{l}\text { Grade } \\
\mathbf{3}\end{array}$ & $\begin{array}{l}\text { Grade } \\
\mathbf{4}\end{array}$ & $\begin{array}{l}\text { Grade } \\
\mathbf{5}\end{array}$ & $\begin{array}{l}\text { Any } \\
\text { Grade }\end{array}$ & $\begin{array}{l}\text { Grade } \\
\mathbf{3}\end{array}$ & $\begin{array}{l}\text { Grade } \\
\mathbf{4}\end{array}$ & $\begin{array}{l}\text { Grade } \\
\mathbf{5}\end{array}$ & Any Grade & $\begin{array}{l}\text { Grade } \\
\mathbf{3}\end{array}$ & $\begin{array}{l}\text { Grade } \\
\mathbf{4}\end{array}$ & $\begin{array}{l}\text { Grade } \\
\mathbf{5}\end{array}$ \\
\hline Pneumonitis & 0 & 0 & 0 & 0 & $1(6)$ & 0 & 0 & 0 & $1(3)$ & 0 & 0 & 0 \\
\hline Esophagitis & $1(6)$ & 0 & 0 & 0 & $1(6)$ & $1(6)$ & 0 & 0 & $3(9)$ & $1(3)$ & 0 & 0 \\
\hline Tracheitis & 0 & 0 & 0 & 0 & $2(12)$ & $2(12)$ & 0 & 0 & $2(6)$ & $2(6)$ & 0 & 0 \\
\hline Chest pain & 0 & 0 & 0 & 0 & $1(6)$ & 0 & 0 & 0 & $1(3)$ & 0 & 0 & 0 \\
\hline Agranulocytosis & 0 & 0 & 0 & 0 & $1(6)$ & 0 & 0 & 0 & $1(3)$ & 0 & 0 & 0 \\
\hline Thrombocytopenia & 0 & 0 & 0 & 0 & $1(6)$ & 0 & 0 & 0 & $1(3)$ & 0 & 0 & 0 \\
\hline Late toxicities & & & & & & & & & & & & \\
\hline Tachycardia & 0 & 0 & 0 & 0 & $1(6)$ & 0 & 0 & 0 & $1(3)$ & 0 & 0 & 0 \\
\hline Lung fibrosis & 0 & 0 & 0 & 0 & $1(6)$ & 0 & 0 & 0 & $1(3)$ & 0 & 0 & 0 \\
\hline $\begin{array}{l}\text { Tracheoesophageal } \\
\text { fistula }\end{array}$ & 0 & 0 & 0 & 0 & $1(6)$ & 0 & 0 & $1(6)$ & $1(3)$ & 0 & 0 & $1(3)$ \\
\hline $\begin{array}{l}\text { Esophageal- } \\
\text { mediastinal fistula }\end{array}$ & 0 & 0 & 0 & 0 & $1(6)$ & 0 & 0 & $1(6)$ & $1(3)$ & 0 & 0 & $1(3)$ \\
\hline
\end{tabular}

Note: Group A: Patients with R/SP-MLNMs who received treatment including surgery and/or chemotherapy, but not radiation therapy; Group B: Patients with R/SP-MLNMs who received treatment including surgery and/or chemotherapy, and radiation therapy

Percent was calculated based on the total enrolled in each group (group A = 16, group B = 17) or the total study (33).
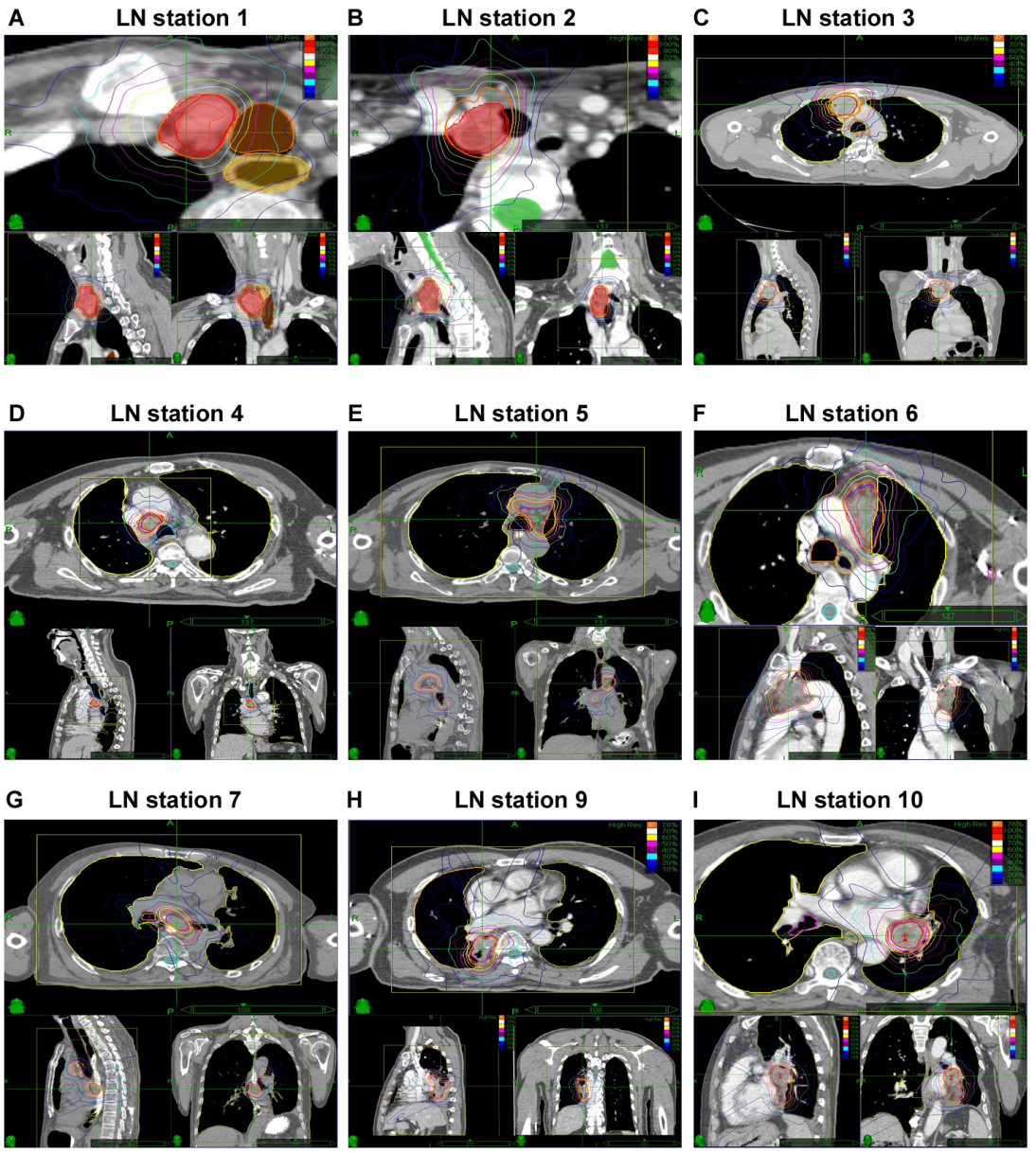

Figure 2: Representative planning CT and isodose distributions with SRT of patients with R/SP-MLNMs originating from NSCLC. The purple and yellow lines indicate GTV and PTV, respectively. (A-I) The LN stations of MLNMs. CT: computer tomography; SRT: stereotactic radiotherapy; R/SP-MLNM: recurrent / second primary mediastinal lymph node metastases; GTV: gross tumor volume; PTV: planning target volume. 
(3D-CRT or IMRT) [36-37], and 16-19 months in patients with unresectable IIIA and IIIB NSCLC receiving concurrent chemo-RT [38-40]. SRT achieves exciting LC rates for R/SP-MLNMs from NSCLC: 1-year and 3-year actuarial LC rates for all eligible patients were 100\% and $85.5 \%$, respectively, improved compared reported rates of conventional RT [36-37]. The reason for these discrepancies may be in part be attributed to the initial stage of patients (e.g. the Will Rogers phenomemon), the number of MLNMs involved, NSCLC histology, patient selection, and other treatments used.

In our series, patients with R/SP-MLNMs who had received prior RT had a shorter median OS compared to those without RT (15.3 months vs. 45 months, in Figure
$5 \mathrm{~B})$, and this may be due to the more aggressive tumor biology, lower prescribed dose, lower dose per fraction, smaller PTV size, or lower $\mathrm{BED}_{10}$ used in Group B compared to those in Group A.

In addition, we found that the interval time between the surgery and SRT was important (Figure 5C). For patients who received SRT $<15.5$ months after their surgery, the median OS was 42.0 months vs. 72.0 months for those treated at $\geq 15.5$ months after surgery. In this retrospective series, a shorter time from surgery until SRT is likely a surrogate of more aggressive recurrent or second primary cancer. The time point of 15.5 months should not be interpreted as an "optimal time" window to deliver RT.
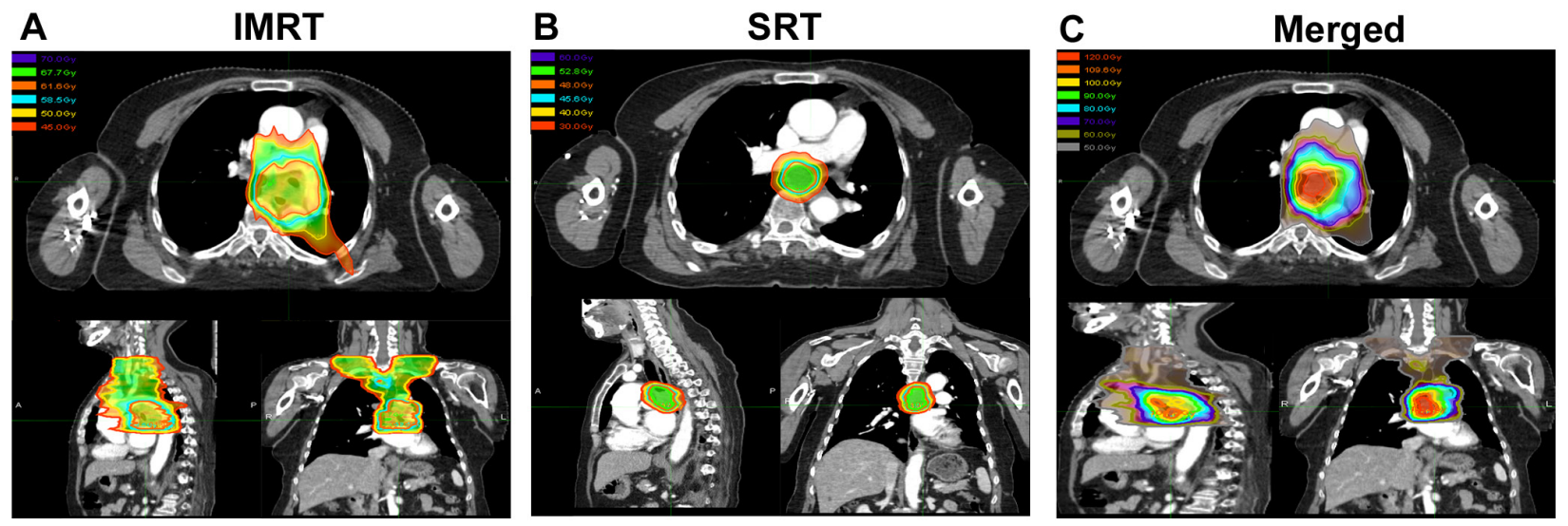

Figure 3: Analysis of SRT, IMRT, and the composite images for a representative patient. In this case, a 64-year-old woman squamous cell lung cancer located in left lower lobe with station 7 MLN, received SRT 6.8 months after completion of IMRT; Unfortunately, the patient died of tracheoesophageal fistula six weeks after completion of SRT. (A) IMRT was delivered in in 28 fractions to a dose of 61.6 Gray for NSCLC of LN station 7; (B) At 6.8 months after completion of IMRT, there was a R-MLNM at station 7; SRT was initiated, in 8 fractions to $48 \mathrm{~Gy}$, prescribed to the $75 \%$ isodose line; (C) Composite plans were created of SRT and IMRT using MIM Software. SRT: stereotactic radiotherapy; IMRT: intensity modulated radiation therapy.

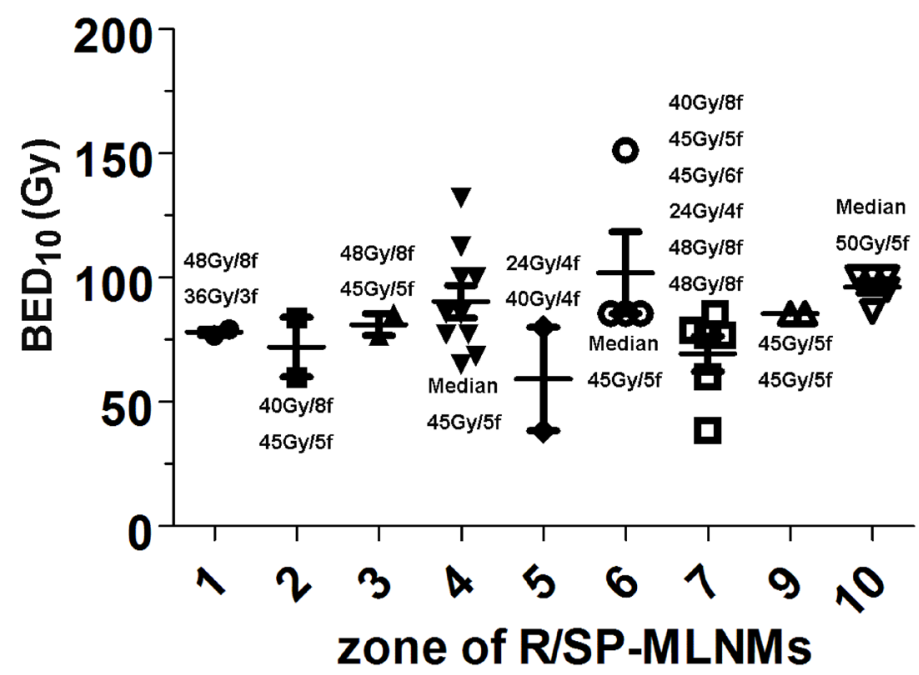

Figure 4: The detailed summary of the prescribed dose, dose per fraction, and BED from each MLNM stations. $\mathrm{BED}_{10}$ : biologically effective dose at an $\alpha / \beta$ of 10 ; R/SP-MLNMs: recurrent or second primary mediastinal lymph node metastases; Gy: Gray; f: fraction. 
There was no significant difference in OS between patients with R-MLNMs vs. SP-MLNMs with respect to interval between surgery and SRT (Figure 5D). In addition, our results were consistent with that of some previous studies, which showed that the OS showed a slight trend towards superiority of SRT with chemo over SRT without chemo, although these differences were not statistically significant [34, 41-42]. We provide the details of chemotherapy in Table 1 . Notably, the number of patients receiving chemotherapy was relatively small (24 patients before SRT; 14 patients after SRT), and these patients may have also received molecular targeted therapy (e.g. erlotinib for EGFR mutations). Chemotherapy regimens were tailored to individual patients: pemetrexed was preferred for adenocarcinoma, and a platinum in combination with gemcitabine was preferred for squamous cell carcinoma. Other agents used included paclitaxel, docetaxel, etoposide, and vinorelbine. The observed superiority of SRT with chemotherapy over SRT alone may be due to a number of factors, including (1) patient performance status and ability to tolerate chemotherapy (and the number of cycles of chemo); (2) histology and potential response to a particular agent; (3) molecular subtype and ability to use molecularly targeted therapy; and (4) synergy of chemotherapy and RT. Based on these considerations, we cannot recommend a particular systemic therapy regimen for all patients, and we encourage clinicians to use personalized approaches.

The treatment of patients with R/SP-MLNMs from NSCLC is a continuing challenge because the disease typically causes symptoms and is usually terminal. The common symptoms for our patients were cough, shortness of breath, hoarseness, and difficulty swallowing, which seriously affect quality of life. After SRT, symptoms improved after a median follow-up of 6 days (range, 3-18) for about half of patients, and there was continued alleviation throughout the follow-up period. Our findings concur with published data where palliative RT may improve pain, cough, hoarse, and dyspnea from recurrent NSCLC [35, 43-44].

In this study, no patient failed within the R/SPMLNM PTV. Five patients (15\%) had no progression after SRT (all in Group A), 17 (52\%; 5 in Group A and 12 in Group B) who had progression, with a median of
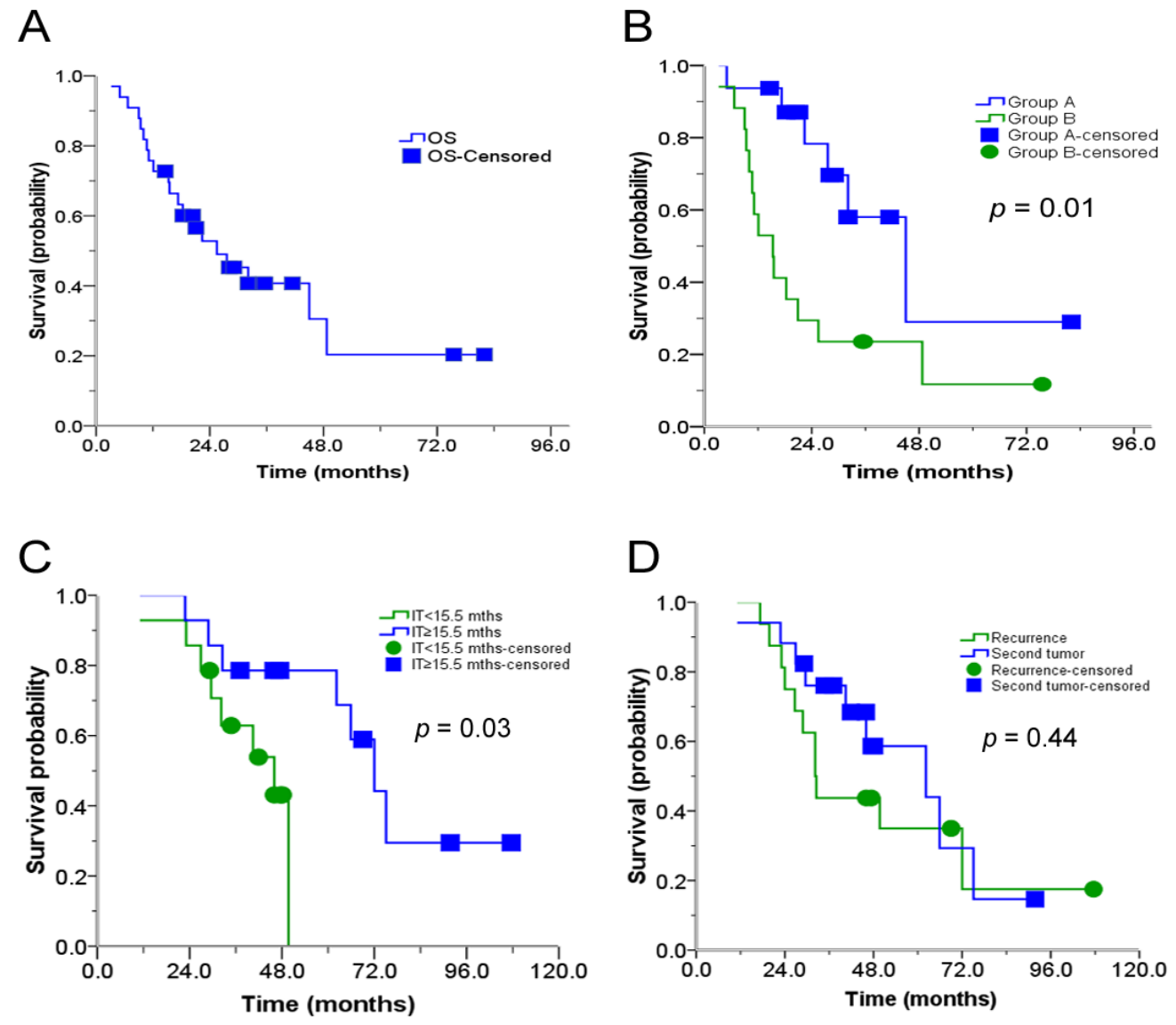

Figure 5: Actuarial OS of patients. (A) OS after receiving SRT; (B) OS after receiving SRT depending on treatment group (Group A is without prior RT; Group B is with prior RT); (C) OS after receiving SRT, depending on the time between surgery and SRT; (D) OS after receiving SRT, depending on R- vs. SP-MLNMs. OS: Overall survival; R/SP-MLNM: recurrent/second primary mediastinal lymph node metastases; SRT: stereotactic radiation therapy; S: surgery; IT: interval time. 
16.9 months after SRT (range, 2.7-75.5 months). The most frequent sites of distant metastases were liver, lung, bone, brain, lymph nodes, and diffuse progression. It is interesting to note that the primary pattern of failure in this patient population would be local failure, had the patients received conventional RT [36, 45-46]. The reason for this discrepancy may be in part be attributed to the improved efficacy of SRT (compared to conventional RT), secondary to the higher prescribed dose, dose per fraction, and $\mathrm{BED}_{10}$. Based on the low incidence of loco-regional failure and high incidence of distant metastasis we observed, we would not recommend elective nodal irradiation in this patient population.

In the present study, SRT toxicities were mild (CTCAE Grade 1-2), with most patients experiencing pneumonitis, esophagitis, tracheitis, chest pain, agranulocytosis, and thrombocytopenia. These symptoms were transient and resolved with conservative management. More severe toxicities occurred more frequently in Group B; moreover, four patients with LN station 7 MLNMs receiving re-RT experienced tachycardia, lung fibrosis, tracheoesophageal fistula, and esophageal-mediastinal fistula. Importantly, 2 patients $(6 \%)$ died from Grade 5 late toxicities. Both were treated to LN station 7: one patient died of tracheoesophageal fistula five weeks after completion of SRT; another patient died of tracheoesophageal fistula six weeks after completion of SRT.

A prospective multicenter dose-escalation trial, RTOG 0813, has provided some normal tissue constraints for consideration when treating tumors near sensitive central structures [25]. Additionally, clinical studies have demonstrated that RT dose, fractionation, dosevolume histogram constraints, as well as administration of systemic therapy are related to toxicity [47-49]. We caution clinicians to consider lymph node station (particularly zone 7) and use of previous RT before administration of SRT for R/SP-MLNMs.

This study had potential weaknesses. It is retrospective in nature, and it contains a relatively small number of patients who were treated over a long time period with heterogeneous fractionation regimens and systemic therapies. RTOG 0813 will help define the role of SBRT for patients with centrally-located lung tumors. We eagerly await the results of RTOG 0813, and we hope our clinical experience will complement its findings. In conclusion, to our knowledge, this is the first study to evaluate the safety and efficacy of SRT (both SBRT and FSRT) in the treatment of patients with R/SP-MLNMs from NSCLC. We recommend clinicians exercise extreme caution in using SRT for R/SP-MLNMs in patients who received prior RT (particularly to LN station 7). For patients without previous RT, SRT appears to be safe and efficacious treatment modality; prospective studies are warranted.

\section{PATIENTS AND METHODS}

\section{Study design and eligible patients}

We queried our prospectively-collected retrospective database of patients with R/SP-MLNMs originating from NSCLC. Patients were treated between October 1, 2006 and July 13, 2013. All patients were examined in a multidisciplinary setting by surgical (CLW), medical (KL), and radiation (MBM, ZYY, and PW) oncologists at the time of diagnosis, and their cases were re-presented in front of the tumor board on an as-needed basis (e.g. at time of recurrence).

The inclusion criteria were defined as follows: (i) any age; (ii) Karnofsky performance score (KPS) $\geq 70$; (iii) R/SP-MLNMs from NSCLC with prior biopsy and histologic confirmation; and either computed tomography (CT) or positron emission tomography/computed tomography (PET-CT) images; (iv) life expectancy $>6$ months; (vi) unamenable to resection (either because of anatomical tumor characteristics or patient comorbidities); and (vii) patient written informed consent for the treatment and database. We defined R-MLNMs as disease that was of the same histology as a previously-treated primary NSCLC. We defined SP-MLNMs as a different histology or having radiographic appearance inconsistent with progression of the original primary.

Exclusion criteria were as follows: contraindication to receiving RT; and uncontrolled comorbid condition (metabolic or psychiatric). The study protocol was in accordance with the ethical guidelines of the 1995 Declaration of Helsinki and was approved by the independent ethics committees at Tianjin Medical University Cancer Institute \& Hospital, National Clinical Research Center for Cancer.

\section{Classification and delineation of R/SP-MLNMs}

The MLN stations were classified according to the definition of Mountain and Dresler [19], and were delineated following the atlas from the University of Michigan [20]. MLNMs were divided into three groups: the upper mediastinal compartment, including stations 1 , 2, 3, and 4; the middle mediastinal compartment, including stations 5 and 6; and the lower mediastinal compartment, including stations 7, 9, and 10 .

\section{Treatment schedule}

The methodology used for CyberKnife SRT and treatment planning has been described in detail in our previous reports [21-23]. Briefly, patients were immobilized using a vacuum bag before CT simulation. 
A set of planning three-dimensional (3D) and fourdimension (4D) CT images were obtained after injection of intravenous radiographic contrast material infusion to highlight the MLNMs. The gross target volume (GTV) was defined as the MLNM disease based on simulation, CT, and/or PET-CT. The planning target volume (PTV) was defined as the GTV with a margin of $0.3 \mathrm{~cm}$ in the $\mathrm{x}, \mathrm{y}$, and $\mathrm{z}$-axis direction. The PTV was also amended to adjacent organs at risk (e.g. esophagus, heart). The Xsight spine tracking system was used for all targets, which carried out positional alignment based on bony spinal skeletal structures. Given the exploratory and retrospective nature of this project, and its span of seven years, the prescribed dose and fractionation were determined based on factors specific to each patient and cancer, including treatment interval since previous RT, patient performance status, target volume, and previous RT dose to the adjacent critical structures. Examples of each LN station dose distribution are shown in Figure 2.

Composite plans were generated of current and prior RT courses as previously described [18]. Dose volume histograms were analyzed, and if dose volume constraints were exceeded, clinical judgment was used to maximize the therapeutic ratio. Composite plans were generated as both an absolute summation of the two plans and with the treated doses converted to biologically effective doses (BEDs) and equivalent doses in 2 Gy fractions (EQD2s). BEDs were calculated based on the formula: $\operatorname{nd}[1+\mathrm{d} /$ $(\alpha / \beta)$ ], where $n$ is number of fractions, and $d$ is dose/ fraction (Gy); assuming $\alpha / \beta$ value of 10 for lung cancer or acute toxicities (i.e. $\mathrm{BED}_{10}$ ), and assuming $\alpha / \beta$ value of 3.0 for late toxicities (i.e. $\left.\mathrm{BED}_{3}\right)$. EQD2s were calculated based on the formula: $\operatorname{nd}((d+\alpha / \beta) /(2+\alpha / \beta))[24]$.

MIM Software (v5.6, MIM Sofware Inc, Cleveland, $\mathrm{OH}$ ) was used to convert dose to the EQD2, fuse scans, and combine the dose files. A sample of composite plan is shown in Figure 3. Normal tissue constraints for SRT planning were limited by constraints proposed by Kong et al., the Radiation Therapy Oncology Group (RTOG) 0236 and 0813 guidelines, and NRG BR-001 guidelines (provided in Supplementary materials 1) [20, 25-27]. In addition, if patients received chemotherapy, data was gathered about the agents used and the number of cycles.

\section{Follow-up}

Patients were seen in clinic at 1 month after completion of treatment, then every 3 months for the first year; then, every 6 months until July 2013. Imaging, adverse events, and compliances of all patients were monitored for the follow-up period using our clinical databases.

\section{Endpoints}

The primary end-point was overall survival (OS), defined as the time between the date of the SRT and the date of death or the date of the last follow-up for censored patients. The secondary end-points were: (1) MLNMs local control rate (LC; defined as no progression of treated disease on follow-up scans), either complete response (CR) or partial response (PR), defined using the RECIST 1.1 Response Evaluation Criteria in Solid Tumors [28], assessed at a minimum of 6 months of follow-up after SRT, in order to avoid uncertainty associated with early transient radiographic changes within the high-dose region; (2) the time to symptom alleviation (defined as the time between the date of the SRT completion and the date of symptom alleviation or the date of the last followup for censored patients); and (3) Common Terminology Criteria for Adverse Events (CTCAE v4.0) grade toxicity. All toxicities were assessed in a multidisciplinary setting. Patients were considered to have a local failure if there was evidence of increased size of enhancing tumor in the treated region. PET-CT scan was employed to assist with differentiating radiation related changes with local or regional recurrence.

\section{Statistical analysis}

OS and LC curves were estimated using KaplanMeier analysis. Curves were compared by using the stratified log-rank test. A $p$ value of 0.05 or less was considered statistically significant. Data were analyzed using the statistical software Intercooled Stata version 8.2 for Windows (Stata Corporation, College Station, Texas, USA).

\section{ACKNOWLEDGEMENTS}

This work was supported by the National Natural Science Foundation of China (No. 81201754), the New Teacher Fund for Doctor Station, the Ministry of Education (No. 20121202120014), the National Natural Science Foundation of China (No. 81472797 and No. 81201753), and the Foundation of National Clinical Research Center for Cancer (No. N14B04). No benefits in any form have been or will be received from a commercial party directly or indirectly related to the subject of this article. We also thank the anonymous reviewer for his/her very helpful comments, which improved the quality of this paper.

\section{FUNDING SOURCES}

This work was supported by the National Natural Science Foundation of China (No. 81201754), the 
New Teacher Fund for Doctor Station, the Ministry of Education (No. 20121202120014), the National Natural Science Foundation of China (No. 81472797 and No. 81201753), and the Foundation of National Clinical Research Center for Cancer (No. N14B04). No benefits in any form have been or will be received from a commercial party directly or indirectly related to the subject of this article.

\section{APPROVAL/DISCLOSURES}

All authors have read and approved the manuscript. We have no financial disclosures. We are not using any copyrighted information, patient photographs, identifiers, or other protected health information in this paper. No text, text boxes, figures, or tables in this article have been previously published or owned by another party. Figure 1 was created by Nicholas G. Zaorsky, MD.

\section{CONFLICT OF INTEREST STATEMENT}

No benefits in any form have been or will be received from a commercial party directly or indirectly related to the subject of this article.

\section{REFERENCES}

1. Sakao Y, Miyamoto H, Yamazaki A, Ou S, Shiomi K, Sonobe S, Sakuraba M. The spread of metastatic lymph nodes to the mediastinum from left upper lobe cancer: results of superior mediastinal nodal dissection through a median sternotomy. Eur J Cardiothorac Surg 2006; 30: 543547.

2. Kelsey CR, Light KL, Marks LB. Pattern of failure after resection of non-small cell lung cancer: implications for postoperative radiation therapy volumes. Int J Radiat Oncol Biol Phys 2006; 65: 1097-1105.

3. Rosenzweig KE, Sim SE, Mychalczak LE, Schindelheim $\mathrm{R}$, Leibel SA. Elective nodal irradiation in the treatment of non-small cell lung cancer with three-dimensional conformal radiation therapy. Int J Radiat Oncol Biol Phys 2001; 50: 681-685.

4. Jeremic B. Incidental irradiation of nodal regions at risk during limited-field radiotherapy (RT) in dose-escalation studies in non-small cell lung cancer (NSCLC). Enough to convert no-elective into elective nodal irradiation (ENI)? Radiother Oncol 2004; 71: 123-125.

5. Chen M, Hayman JA, Ten Haken RK, Tatro D, Fernando S, Kong FM. Long-term results of high-dose conformal radiotherapy for patients with medically inoperable $\mathrm{T} 1$ 3N0 non-small cell lung cancer: is low incidence of regional failure due to incidental nodal irradiation? Int J Radiat Oncol Biol Phys 2006; 64: 120-126.

6. Zhao L, Chen M, Ten Haken R, Chetty I, Chapet O, Hayman JA, Kong FM. Three-dimensional conformal radiation may deliver considerable dose of incidental nodal irradiation in patients with early stage node-negative nonsmall cell lung cancer when the tumor is large and centrally located. Radiother Oncol 2007; 82: 153-159.

7. Kepka L, Bujko K, Zolciak-Siwinska A. Risk of isolated nodal failure for non-small cell lung cancer (NSCLC) treated with the elective nodal irradiation (ENI) using 3D-conformal radiotherapy (3D-CRT) techniques-a retrospective analysis. Acta Oncol 2008; 47: 95-103.

8. Casali C, Stefani A, Natali P, Rossi G, Morandi U. Prognostic factors in surgically resected N2 non-small cell lung cancer: the importance of patterns of mediastinal lymph nodes metastases. Eur J Cardiothorac Surg 2005; 28 : 33-38.

9. Noble J, Ellis PM, Mackay JA, Evans WK, Lung cancer disease site group of cancer care ontario's program in evidence-based care. Second-line or subsequent systemic therapy for recurrent or progressive non-small cell lung cancer: a systematic review and practice guideline. J Thorac Oncol 2006; 1: 1042-1058.

10. Salah S, Tanvetyanon T, Abbasi S. Metastatectomy for extra-cranial extra-adrenal non-small cell lung cancer solitary metastases: Systematic review and analysis of reported cases. Lung cancer 2012; 75: 9-14.

11. NCCN Clinical Practice Guidelines in Non-small cell lung cancer (Version 1. 2015). Available at www.nccn.org.

12. Sonobe M, Yamada T, Sato M, Menju T, Aoyama A, Sato T, Chen F, Omasa M, Bando T, Date H. Identification of subsets of patients with favorable prognosis after recurrence in completely resected non-small cell lung cancer. Ann Surg Oncol 2014; 21: 2546-2554.

13. Wu KL, Jiang GL, Qian H, Wang LJ, Yang HJ, Fu XL, Zhao S. Three-dimensional conformal radiotherapy for locoregionally recurrent lung carcinoma after external beam irradiation: a prospective phase I-II clinical trial. Int J Radiat Oncol Biol Phys 2003; 57: 1345-1350.

14. Kelly P, Balter PA, Rebueno N, Sharp HJ, Liao Z, Komaki $\mathrm{R}$, Chang JY. Stereotactic body radiation therapy for patients with lung cancer previously treated with thoracic radiation. Int J Radiat Oncol Biol Phys 2010; 78: 13871393.

15. Peulen H, Karlsson K, Lindberg K, Tullgren O, Baumann P, Lax I, Lewensohn R, Wersall P. Toxicity after reirradiation of pulmonary tumors with stereotactic body radiotherapy. Radiother Oncol 2011; 101: 260-266.

16. Trakul N, Harris JP, Le QT, Hara WY, Maxim PG, Loo BW Jr, Diehn M. Stereotactic ablative radiotherapy for reirradiation of locally recurrent lung tumors. J Thorac Oncol 2012; 7: 1462-1465.

17. Seung SK, Solhjem M. Salvage SBRT for previously irradiated lung cancer. J Cancer Ther 2011; 2: 190-195.

18. Kilburn JM, Kuremsky JG, Blackstock AW, Munley MT, Kearns WT, Hinson WH, Lovato JF, Miller AA, Petty WJ, Urbanic JJ. Thoracic re-irradiation using stereotactic body 
radiotherapy (SBRT) techniques as first or second course of treatment. Radiother Oncol 2014; 110: 505-510.

19. Mountain CF, Dresler CM. Regional lymph node classification for lung cancer staging. Chest 1997; 111: 1718-1723.

20. Kong FM, Ritter T, Quint DJ, Senan S, Gaspar LE, Komaki RU, Hurkmans CW, Timmerman R, Bezjak A, Bradley JD, Movsas B, Marsh L, Okunieff P, Choy H, Curran WJ Jr. Consideration of dose limits for organs at risk of thoracic radiotherapy: atlas for lung, proximal bronchial tree, esophagus, spinal cord, ribs, and brachial plexus. Int J Radiat Oncol Biol Phys 2011; 81: 1442-1457.

21. Yuan Z, Tian L, Wang P, Song Y, Dong Y, Zhuang H. Comparative research on the efficacy of CyberKnife and surgical excision for stage I hepatocellular carcinoma. Onco Targets Ther 2013; 6: 1527-1532.

22. Yuan ZY, Meng MB, Liu CL, Wang HH, Jiang C, Song YC, Zhuang HQ, Yang D, Wang JS, Wei W, Li FT, Zhao LJ, Wang P. Stereotactic body radiation therapy using the CyberKnife system for patients with liver metastases. Onco Targets Ther 2014; 7: 915-923.

23. Zhuang HQ, Yuan ZY, Song YC, Wang J, Zhao LJ, Wang P. Clinical observation on the efficacy of CyberKnife for primary or metastatic retroperitoneal tumors. Eur J Cancer Care (Engl) 2014; 23: 76-81.

24. Meijneke TR, Petit SF, Wentzler D, Hoogeman M, Nuyttens JJ. Reirradiation and stereotactic radiotherapy for tumors in the lung: dose summation and toxicity. Radiother Oncol 2013; 107: 423-27.

25. Timmerman R, Paulus R, Galvin J, Michalski J, Straube W, Bradley J, Fakiris A, Bezjak A, Videtic G, Johnstone D, Fowler J, Gore E, Choy H. Stereotactic body radiation therapy for inoperable early stage lung cancer. JAMA 2010; 303: 1070-1076.

26. Radiation Therapy Oncology Group. RTOG 0813: Seamless phase I/II study of stereotactic lung radiotherapy (SBRT) for early stage, centrally located, non-small cell lung cancer (NSCLC) in medically inoperable patients. Available at http://www.rtog.org/ClinicalTrials/ProtocolTable/ StudyDetails.aspx?study $=0813$.

27. NRG Oncology. A phase 1 study of stereotactic body radiotherapy (SBRT) for the treatment of multiple metastases. Available at https://clinicaltrials.gov/ct2/show/ NCT02206334?term=NRG-BR001\&rank=1

28. Eisenhauer EA, Therasse P, Bogaerts J, Schwartz LH, Sargent D, Ford R, Dancey J, Arbuck S, Gwyther S, Mooney M, Rubinstein L, Shankar L, Dodd L, Kaplan R, Lacombe D, Verweij J. New response evaluation criteria in solid tumors: revised RECIST guideline (version 1.1). Eur J Cancer 2009; 45: 228-247.

29. Harpole DH Jr, Herndon JE 2nd, Young WG Jr, Wolfe WG, Sabiston DC Jr. Stage I nonsmall cell lung cancer: A multivariate analysis of treatment methods and patterns of recurrence. Cancer 1995; 76: 787-96.
30. Trodella L, Trodella L, Granone P, Valente S, Valentini V, Balducci M, Mantini G, Turriziani A, Margaritora S, Cesario A, Ramella S, Corbo GM, D'Angelillo RM, Fontana A, Galetta D, Cellini N. Adjuvant radiotherapy in non-small cell lung cancer with pathological stage I: definitive results of a phase III randomized trial. Radiother Oncol 2002; 62: 11-19.

31. The Lung Cancer Study Group. Effects of postoperative mediastinal radiation on completely resected stage II and stage III epidermoid cancer of the lung. N Engl J Med 1986; 315: 1377-1381.

32. Dautzenberg B, Arriagada R, Chammard AB, Jarema A, Mezzetti M, Mattson K, Lagrange JL, Le Pechoux C, Lebeau B, Chastang C. A controlled study of postoperative radiotherapy for patients with completely resected nonsmall cell lung carcinoma. Groupe d'Etude et de Traitement des Cancers Bronchiques. Cancer 1999; 86: 265-273.

33. Curran WJ Jr, Herbert SH, Stafford PM, Sandler HM, Rosenthal SA, McKenna WG, Hughes E, Dougherty MJ, Keller S. Should patients with post-resection locoregional recurrence of lung cancer receive aggressive therapy? Int J Radiat Oncol Biol Phys 1992; 24: 25-30.

34. Kagami Y, Nishio M, Narimatsu N, Mjoujin M, Sakurai T, Hareyama M, Saito A. Radiotherapy for locoregional recurrent tumors after resection of non-small cell lung cancer. Lung cancer 1998; 20: 31-35.

35. Jeremic B, Shibamoto Y, Milicic B, Milisavljevic S, Nikolic N, Dagovic A, Aleksandrovic J, Radosavljevic-Asic G. External beam radiation therapy alone for loco-regional recurrence of non-small-cell lung cancer after complete resection. Lung cancer 1999; 23: 135-142.

36. Kelsey CR, Clough RW, Marks LB. Local recurrence following initial resection of NSCLC: salvage is possible with radiation therapy. Cancer J 2006; 12: 283-288.

37. Wagner $\mathrm{H} \mathrm{Jr}$. Thoracic irradiation for patients with resected non-small cell lung cancer: adjuvant or salvage? Cancer J 2006; 12: 253-256.

38. Belani CP, Choy H, Bonomi P, Scott C, Travis P, Haluschak J, Curran WJ Jr. Combined chemoradiotherapy regimens of pacitaxel and carboplatin for locally advanced non-small cell lung cancer: a randomized phase II locally advanced multi-modality protocol. J Clin Oncol 2005; 23: 5883-5891.

39. Ournel P, Robinet G, Thomas P, Souquet PJ, Lena H, Vergnenegre A, Delhoume JY, Le Treut J, Silvani JA, Dansin E, Bozonnat MC, Daures JP, Mornex F, Perol M, Groupe Lyon-Saint-Etienne d'Oncologie ThoraciqueGroupe Francais de Pneumo-Cancerologie. Randomized phase III trial of sequential chemoradiotherapy compared with concurrent chemoradiotherapy in locally advanced non-small-cell lung cancer: Groupe Lyon-Saint-Etienne d'Oncologie Thoracique-Groupe Français de PneumoCancérologie NPC 95-01 study. J Clin Oncol 2005; 23: 5910-5917.

40. Huber RM, Flentje M, Schmidt M, Pollinger B, Gosse H, Willner J, Ulm K, Bronchial Carcinoma Therapy 
Group. Simultaneous chemoradiotherapy compared with radiotherapy alone after induction chemotherapy in inoperable stage IIIA or IIIB non-small-cell lung cancer: study CTRT99/97 by the Bronchial Carcinoma Therapy Group. J Clin Oncol 2006; 24: 4397-4404.

41. Shaw EG, Brindle JS, Creagan ET, Foote RL, Trastek VF, Buskirk SJ. Locally recurrent non-small-cell lung cancer after complete surgical resection. Mayo Clin Pro 1992; 67: 1129-1133.

42. Yano T, Hara N, Ichinose Y, Asoh H, Yokoyama H, Ohta M, Hata K. Local recurrence after complete resection for non-small cell carcinoma of the lung: significance of local control by radiation treatment. J Thorac Cardiovasc Surg 1994; 107: 8-12.

43. Lutz ST, Huang DT, Ferguson CL, Kavanagh BD, Tercilla $\mathrm{OF}, \mathrm{Lu}$ J. A retrospective quality of life analysis using the lung cancer symptom scale in patients treated with palliative radiotherapy for advanced non-small cell lung cancer. Int J Radiat Oncol Biol Phys 1997; 37: 117-122.

44. Gressen EL, Werner-Wasik M, Cohn J, Topham A, Curran WJ Jr. Thoracic reirradiation for symptomatic relief after prior radiotherapeutic management for lung cancer. Am J Clin Oncol 2000; 23: 160-163.

45. Kopelson G, Choi NCH. Radiation therapy for postoperative local-regionally recurrent lung cancer. Int J Radiat Oncol Biol Phys 1980; 6: 1503-1506.

46. Curran WJ Jr, Herbert SH, Stafford PM, Sandler HM, Rosenthal SA, McKenna WG, Hughes E, Dougherty MJ, Keller S. Should patients with post-resection locoregional recurrence of lung cancer receive aggressive therapy? Int J Radiat Oncol Biol Phys 1992; 24: 25-30.

47. Wu AJ, Williams E, Modh A, Foster A, Yorke E, Rimner A, Jackson A. Dosimetric predictors of esophageal toxicity after stereotactic body radiotherapy for central lung tumors. Radiother Oncol 2014; DOI: 10.1016/j.radonc.2014.07.001.

48. Corradetti MN, Haas AR, Rengan R. Central-airway necrosis after stereotactic body radiation therapy. N Eng J Med 2012; 366: 2327-2329.

49. Cannon DM, Mehta MP, Adkison JB, Khuntia D, Traynor AM, Tome WA, Chappell RJ, Tolakanahalli R, Mohindra P, Bentzen SM, Cannon GM. Dose-limiting toxicity after hypofractionated dose-escalated radiotherapy in non-smallcell lung cancer. J Clin Oncol 2013; 31: 4343-4348. 